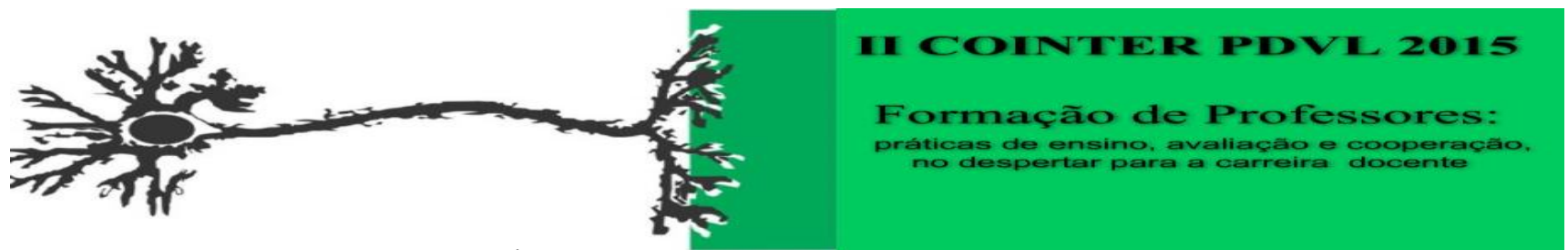

\title{
PROJETO FIC SUSTENTÁVEL: EDUCAÇÃO AMBIENTAL, SUSTENTABILIDADE E CIDADANIA NA ESCOLA ESTADUAL PROFESSOR FRANCISCO IVO CAVALCANTI EM NATAL/RN
}

\author{
Apresentação: Comunicação Oral \\ André Elias de Oliveira Nóbrega ${ }^{1}$; Maria de Lourdes Penha Santos ${ }^{2}$; João Batista dos Santos ${ }^{3}$; \\ Brenda Luiza Patriota Lima e Silva ${ }^{4}$ : Maria Cristina Cavalcanti Araújo ${ }^{5}$
}

\section{Resumo}

Este trabalho tem como objetivo apresentar o projeto de educação ambiental, sustentabilidade e cidadania, desenvolvido pelos alunos-bolsistas do PIBID - Programa de Bolsa de Iniciação à Docência - de Geografia do IFRN Campus Natal Central, na Escola Estadual Professor Francisco Ivo Cavalcanti, em Natal-RN. O PIBID está presente na referida escola desde 2009, possibilitando aos alunos-bolsistas do curso superior de Licenciatura em Geografia do IFRN, a oportunidade de concretizar uma etapa fundamental da formação de professores unindo teoria à prática. Neste sentido, em 2013, surgiu a intenção de promover a alfabetização ambiental, aliada à cidadania, com os alunos do ensino médio da referida escola. O projeto intitulado FIC Sustentável propõe um processo contínuo de reeducação cidadã, fundamentada na ética ambiental centrada na preocupação com as futuras gerações. O projeto visa proporcionar aos alunos, professores e funcionários um ambiente mais limpo e harmonioso dentro das dependências físicas da escola. Para isso, realizou-se uma série de atividades que mobilizaram a comunidade escolar para despertar a questão ambiental, fazendo-os repensar suas práticas cotidianas e tornando o ambiente escolar mais propício para a convivência harmoniosa com o meio ambiente. Metodologicamente, o projeto foi desenvolvido em quatro etapas, a saber: na primeira, partiu-se da observação da escola, onde percebeu-se a necessidade de realizar um projeto de educação ambiental; na segunda etapa realizou-se-pesquisa bibliográfica acerca do tema, para embasar a produção e aplicação de oficinas; na terceira etapa, aplicou-se as atividades/oficinas planejadas em todas as turmas da escola e; na quarta e última etapa, ocorreu a sistematização e análise dos resultados obtidos com o projeto durante os anos de 2014 e 2015 para elaboração de uma coletânea contendo os planos de atividades que podem ser utilizadas nas mais diversas disciplinas, como tema transversal. O projeto é contínuo e permanece em fase de realização, contudo, observa-se resultados positivos já alcançados, como, por exemplo, um maior interesse por parte dos professores e educandos em manter os espaços comuns da escola mais limpos e agradáveis a todos, havendo também um despertar para uma conscientização ambiental que antes passava despercebido por parte dos alunos. Os alunos puderam compreender que a partir de pequenas atitudes contribui-se para fazer do mundo um lugar melhor e mais sustentável. Almejase, dessa forma, que os alunos possam ser multiplicadores dessa ideia e reproduzi-la em seus ambientes de vivência pessoal (casa, rua, grupos etc).

Palavras-Chave: Geografia, PIBID, Educação Ambiental, Sustentabilidade.

\section{Introdução}

\footnotetext{
${ }^{1}$ Licenciando em Geografia, IFRN, andrenobrega999@gmail.com

${ }^{2}$ Licenciando em Geografia, IFRN, lourdespenha1@hotmail.com

${ }^{3}$ Licenciando em Geografia, IFRN, joaoseneca@yahoo.com.br

${ }^{4}$ Licenciando em Geografia, IFRN, brendapatriota7@gmail.com

${ }^{5}$ Doutora em Recursos Naturais, IFRN, cristina.cavalcanti@ifrn.edu.br
} 
Diante das transformações sociais e ambientais vivenciadas principalmente nas últimas décadas no mundo se faz necessária a promoção, nas instituições de ensino, de uma prática educativa voltada para a conscientização ambiental e social. Segundo Ramos e Ramos (2008), os desafios da sociedade contemporânea são complexos e exigem ações coletivas que possam redefinir nossas relações produtivas, cultural e social oportunizando uma vivência mais sustentável. Diante disso, os bolsistas do Programa Institucional de Bolsa de Iniciação à Docência - PIBID ${ }^{6}$, subprojeto Geografia do Campus Natal Central do IFRN, desenvolveram um projeto interdisciplinar abrangendo educação ambiental, sustentabilidade e cidadania na Escola Estadual Professor Francisco Ivo Cavalcanti.

O PIBID de Geografia está presente na Escola Estadual Professor Francisco Ivo Cavalcanti desde o ano de 2009, na qual os alunos do curso superior de Licenciatura em Geografia do Instituto Federal de Educação, Ciência e Tecnologia do Rio Grande do Norte têm a oportunidade de concretizar uma etapa fundamental na formação de professores: a união da teoria à prática. Em 2013, surgiu a intenção de promover uma espécie de alfabetização ambiental com os alunos do ensino médio da escola supracitada. O projeto intitulado FIC Sustentável ${ }^{7}$, da junção das iniciais do nome da escola, propõe um processo contínuo de reeducação cidadã, fundamentada na ética ambiental, de que devemos nos preocupar com aqueles que estão por vir. Para tal, preocupamo-nos em realizar uma série de atividades que mobilizam a comunidade escolar para o despertamento da questão ambiental, fazendo-os repensar suas práticas cotidianas e tornando o ambiente escolar mais propício para a convivência harmoniosa com o meio ambiente.

\section{Fundamentação Teórica}

A proposta teórica que embasou a produção do Projeto FIC Sustentável e posteriormente a produção deste artigo se baseou na concepção de Sato (2002, p. 25), na qual ela frisa que

Há diferentes formas de incluir a temática ambiental nos currículos escolares, como atividades artísticas, experiências práticas, atividades fora de sala de aula, produção de materiais locais, projetos ou qualquer outra atividade que conduza os alunos a serem reconhecidos como agentes ativos no processo que norteia a política ambientalista. Cabe aos professores, por intermédio de prática interdisciplinar,

\footnotetext{
${ }^{6}$ O Programa Institucional de Bolsa de Iniciação à Docência é um programa do Governo Federal mantido pela Coordenação de Aperfeiçoamento de Pessoal de Nível Superior (CAPES), autarquia pública de pesquisa vinculada ao Ministério da Educação-MEC. O programa oferece bolsas de iniciação à docência aos alunos de cursos presenciais que se dediquem ao estágio nas escolas públicas e que, quando graduados, se comprometam com o exercício do magistério na rede pública. O objetivo é antecipar o vínculo entre os futuros mestres e as salas de aula da rede pública. Com essa iniciativa, o PIBID faz uma articulação entre a educação superior (por meio das licenciaturas), a escola e os sistemas estaduais e municipais.

${ }^{7}$ FIC é a sigla formada com as inicias do patrono da escola. É comum na instituição a utilização da sigla como, por exemplo, na farda dos alunos, por isso adotou-se a sigla no projeto já que a mesma faz parte da identidade cultural da instituição.
} 
proporem novas metodologias que favoreçam a implementação da Educação Ambiental, sempre considerando o ambiente imediato, relacionado a exemplos de problemas atualizados.

A educação ambiental pode, assim, ser incluída em todo o processo educacional na qual sua finalidade é o despertar de consciência dos alunos para um assunto que diz respeito a ação humana em seu cotidiano.

Dessa forma, o PIBID de Geografia visou implantar na escola momentos de reflexão e discussão sobre educação ambiental em um sentido amplo e interdisciplinar desenvolvendo um currículo escolar voltado para a questão ambiental, proporcionando a participação de todos no processo de sua construção e execução, tendo os alunos como sujeitos do processo.

Nesse sentido, Narcizo (2009, p. 92) diz que,

Projetos impostos por pequenos grupos ou atividades isoladas, gerenciadas por apenas alguns indivíduos da comunidade escolar - como um projeto de coleta seletiva no qual a única participação dos discentes seja jogar o lixo em latões separados, envolvendo apenas um professor coordenador - não são capazes de produzir a mudança de mentalidade necessária para que a atitude de reduzir o consumo, reutilizar e reciclar resíduos sólidos se estabeleça e transcenda para além do ambiente escolar. Portanto, deve-se buscar alternativas que promovam uma contínua reflexão que culmine na metanóia (mudança de mentalidade); apenas dessa forma, conseguiremos implementar, em nossas escolas, a verdadeira Educação Ambiental, com atividades e projetos não meramente ilustrativos, mas fruto da ânsia de toda a comunidade escolar em construir um futuro no qual possamos viver em um ambiente equilibrado, em harmonia com o meio, com os outros seres vivos e com nossos semelhantes.

Assim, quando pensamos em educação ambiental, devemos atentar que a prática do que se propõe não se dá por atividades pontuais, mas por toda uma mudança de paradigmas que exige uma contínua reflexão e apropriação dos valores que remetem a ela.

\section{Metodologia}

Esta é uma pesquisa de caráter qualitativo que utilizou como ferramenta de coleta de dados a pesquisa bibliográfica e a construção de um projeto de educação ambiental voltado para a sensibilização/conscientização da comunidade escolar em prol de transformar o ambiente escolar mais harmonioso. A metodologia utilizada neste projeto foi desenvolvida através de procedimentos realizados em quatro etapas. Na primeira abordamos a situação problema a partir da observação da escola campo de atuação, onde percebemos a necessidade de realizar um projeto de educação ambiental; concomitante, na segunda etapa, foi realizado levantamento de dados levantamento de dados teóricos, que subsidiaram a estruturação do projeto, mediante uma seleção de músicas, vídeos e poesias, assim como, a elaboração dos nossos instrumentos metodológicos, como questionários, materiais de divulgação, material de apoio e planejamento das ações a serem realizadas na etapa 
seguinte. A terceira etapa consistiu na realização das atividades/oficinas planejadas em todas as turmas da escola: com gincanas, competições, oficinas de reciclagem, rodas de discussão, aulas de campo e aulas temáticas envolvendo Geografia e meio ambiente. Na quarta e última etapa, fizemos a sistematização e análise dos resultados obtidos com o projeto durante os anos de 2014 e 2015 culminando com a elaboração de uma coletânea contendo os planos de atividades, os quais outros professores podem utilizar em suas aulas para trabalharem este tão importante tema transversal à nossa disciplina.

Ao fim das apresentações das oficinas foi solicitado aos alunos da escola que, em grupo, formulassem frases que expressassem o conteúdo exposto durante a oficina. As frases elaboradas foram selecionadas e adesivas nas lixeiras ecológicas espalhadas inicialmente pelo pátio da escola e posteriormente pelos demais espaços.

\section{Resultados e Discussão}

Sabe-se que a preocupação com a sustentabilidade e a manutenção dos recursos terrestres devem ser as regras a serem seguidas para toda e qualquer atividade humana. É crescente a importância da implementação da educação ambiental nas escolas. Para isso não é preciso modificar o currículo com a criação de uma disciplina nova que a aborde, mas sim a correta abordagem dos temas transversais relacionados às disciplinas já existentes, sobretudo a Geografia.

Trabalhar a interdisciplinaridade atrelada a este tema traz a possibilidade de formar cidadãos mais conscientes e críticos, capazes de refletir sobre suas ações e de identificar os problemas presentes na sociedade, para que assim se alcance um futuro melhor para as gerações vindouras.

Para isso, a escola deve fornecer mais do que conceitos, oportunidades para que os alunos possam desenvolver atitudes de solidariedade, hábitos de higiene pessoal e nos diversos ambientes de convivência na escola, e que juntos a comunidade escolar possa transformar o ambiente em um local saudável. O tema Meio Ambiente nos Parâmetros Curriculares Nacionais encontra-se integrado em quase todas as disciplinas que compõe o currículo escolar, no entanto, é trabalhado de forma fragmentada. Portanto, é necessário pensar em procedimentos que trabalhem este tema.

Logo, o PIBID de Geografia na Escola Estadual Professor Francisco Ivo Cavalcanti, buscou referências em diversos artigos científicos e nos PCN's que subsidiassem a estruturação do projeto FIC Sustentável. Após o estudo realizado na escola, foram propostos os seguintes objetivos para o projeto em questão:

- $\quad$ Fortalecer ideias e valores que contribuem para a formação de um cidadão global;

- Disseminar conceitos básicos de meio ambiente e educação ambiental; 
- Desenvolver atividades interativas que buscam a melhoria do ambiente escolar.

Para alcançar estes objetivos, propôs-se realizar as seguintes ações:

- $\quad$ Revitalização da entrada da escola com plantio de mudas nativas;

- $\quad$ Implantação de lixeiras ecológicas nas áreas de convivência (Figura 1);

Figura 1: Lixeira ecológica. Fonte: Própria.

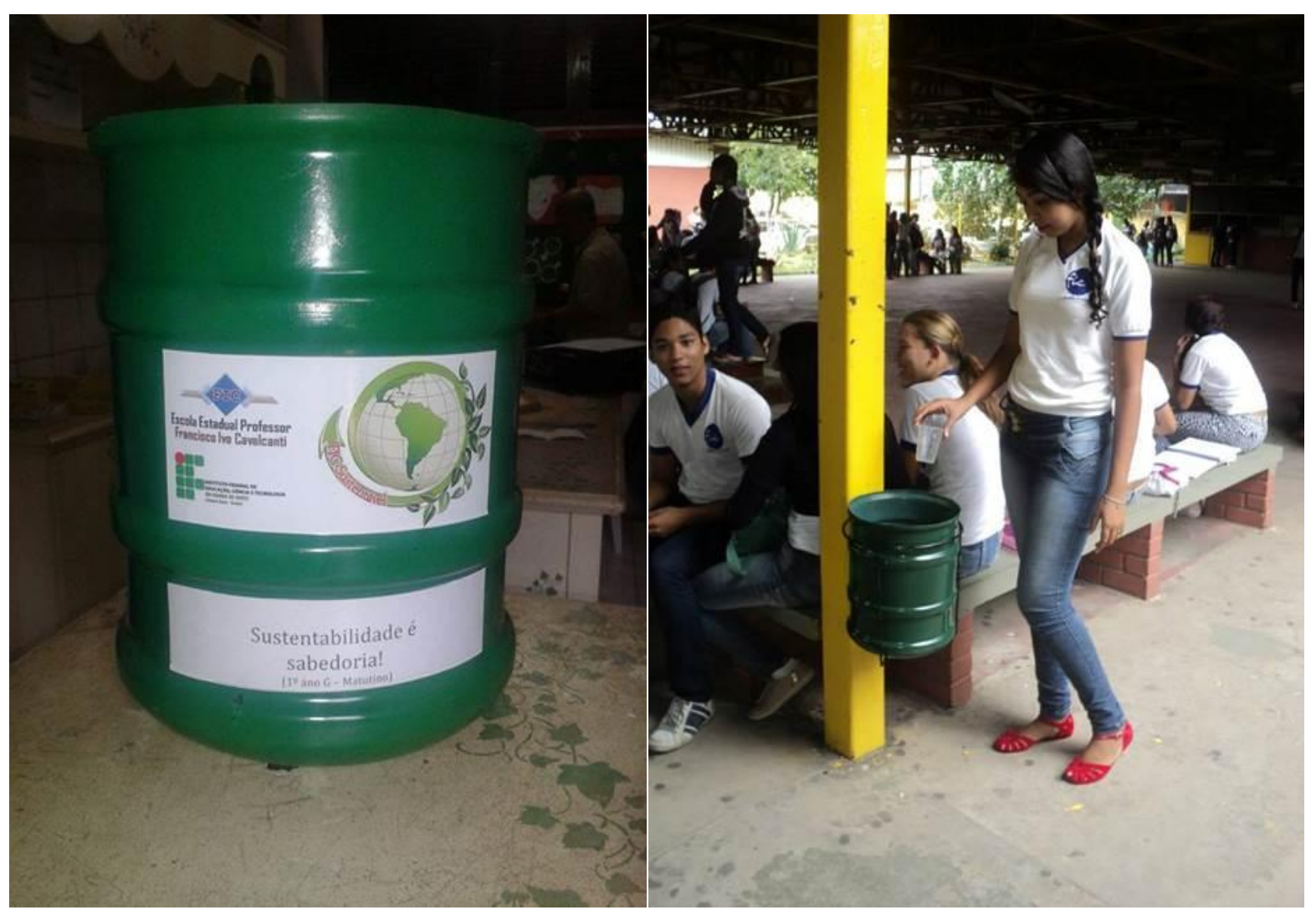

- Momentos de reflexão sobre as práticas ambientais corretas;

- Oficinas de reciclagem;

- Oficinas sobre ecossistemas e biomas;

- Aulas de campo no estuário do Rio Potengi e na unidade de conservação ambiental do Parque Nacional das Dunas em Natal-RN;

- $\quad$ Produção e divulgação no jornal Geografia do Ivo (Figura 2). 
Figura 2: Jornal “Geografia do Ivo”. Fonte: Própria

\section{CAIU NO ENEM!}

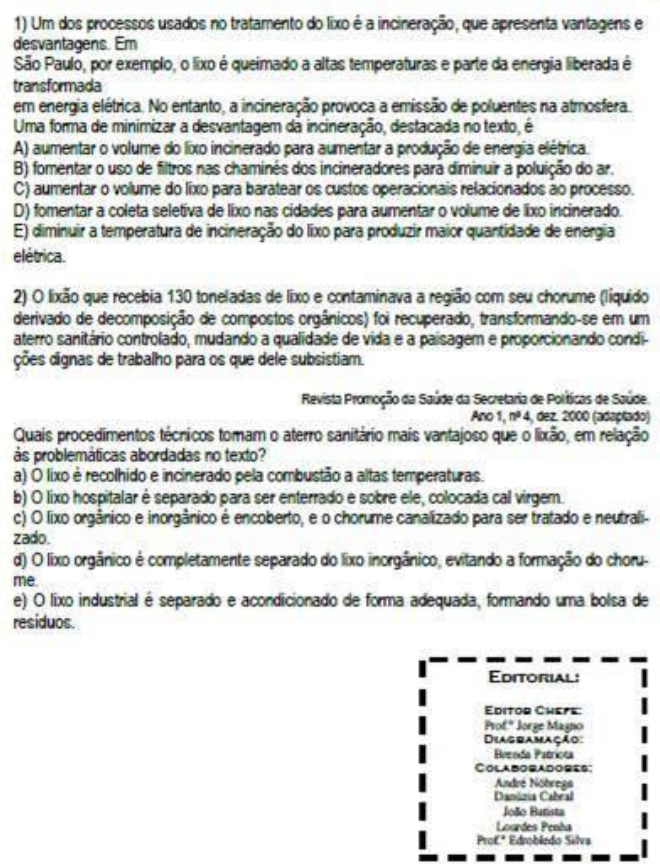

GEOGRAFIA DO IVO

O JORNAL DO ALUNO CRITICO!

ANO $3, N=04-J U L H O / 2014$
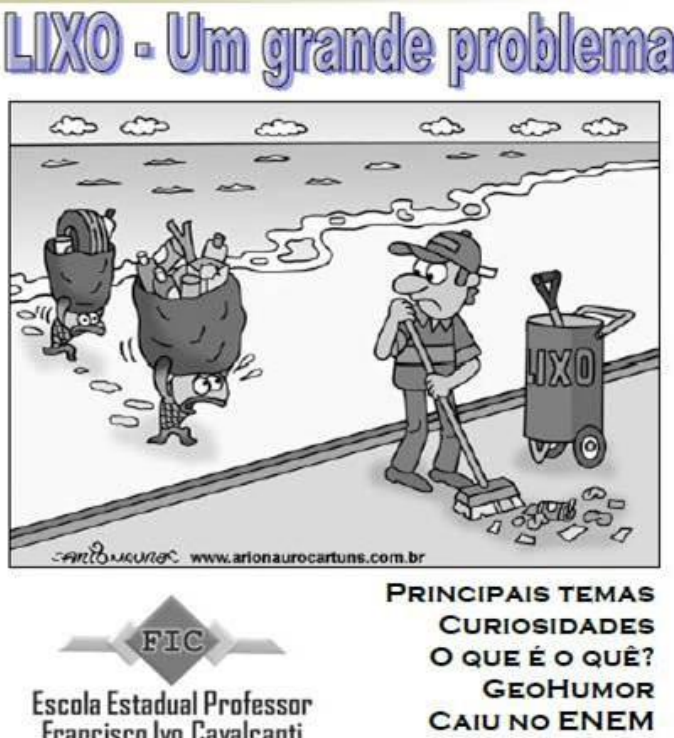

A seleção e elaboração das atividades realizadas durante o projeto têm como áreas de interesse ações que conduzissem ao consumo consciente de energia e água dentro e fora do ambiente escolar; a redução, reutilização e a reciclagem de resíduos, a partir da destinação e tratamento correto do lixo; a manutenção das áreas verdes já existentes na escola e a sua ampliação; a integração das práticas docentes de forma interdisciplinar com objetivo de fornecer aos alunos momentos de reflexão e vivência.

Como exemplo de algumas de nossas atividades, iniciamos ações do projeto com a exibição do documentário A História das Coisas com o intuito de levar os alunos a refletirem sobre o sistema vigente e a sociedade de consumo estabelecida desde a revolução industrial. Assim, eles poderiam pensar e perceber as consequências que este "progresso" causou, portanto, contribuiríamos para a formação de uma nova mentalidade, apta a participar de forma consciente da construção do ambiente em que vive.

Em outro momento, ainda dentro das ações do projeto, foi realizada uma oficina utilizandose o curta metragem de animação Garbage, o qual propõe a construção de um mundo global, onde o homem faz parte da natureza e de todos os fenômenos a ela interligados, sejam estes sociais, biológicos, culturais, políticos ou econômicos. Esta animação também trata da questão ambiental, pois faz crítica ao modo de consumo contemporâneo, relacionando, portanto, às discussões que vinham sendo realizadas já em outros momentos do projeto.

Desse modo, espera-se que o projeto, por meio da Educação Ambiental, possibilite que o 
aluno seja um cidadão consciente de seus atos, preocupado com os problemas associados ao meio ambiente, que identifique tais problemas em seu cotidiano e que desenvolva ações individuais e coletivas tendo em vista solucioná-los. Assim, no decorrer do projeto os alunos foram estimulados a identificar os problemas ambientais da escola e propor soluções, as quais são colocadas em prática. Como forma de incentivo foi definido que aqueles alunos que apresentassem maior envolvimento com as atividades e quisessem se juntar ao grupo do PIBID, seriam nomeados Embaixadores da Sustentabilidade, e atuariam "fiscalizando" o comportamento dos demais alunos para que durante as competições o grupo mais "consciente" fosse pontuado, enquanto que aquele que apresentou ações contraditórias ao conceito de sustentabilidade seriam levados à um momento de reflexão sobre seus atos.

As práticas realizadas tem por finalidade fazer os alunos perceberem que o meio ambiente corresponde à junção dos componentes físicos e sociais, desenvolvendo uma ética ambiental democrática e solidária, na qual exista uma relação de respeito com a natureza e com o ambiente construído em que eles convivem e que essas atitudes sejam extensivas ao cotidiano, seja no convívio familiar ou social.

Neste caso, a mudança no ambiente escolar foi primordial para que se estabelecesse um compromisso entre os jovens envolvidos para levarem suas ações além do espaço escolar.

\section{Conclusões}

O projeto FIC Sustentável foi iniciativa dos bolsistas do PIBID de Geografia do IFRN na Escola Estadual Professor Francisco Ivo Cavalcanti, o qual buscou despertar a educação ambiental dos alunos do ensino médio da referida escola com ações práticas nos espaços físicos da instituição de ensino visando melhorar a qualidade de vida da escola e dos alunos por meio de atitudes ambientalmente corretas. No tocante a atuação dos bolsistas do PIBID, o projeto possibilitou o despertar para atuação de forma prática e efetiva fazendo uma intervenção na escola, a qual surtiu efeitos positivos, estimulando na condução do projeto e a seguir na prática docente.

O projeto permanece em fase de realização, posto que a intenção é que ele seja contínuo, entretanto, já foram observados resultados positivos, como por exemplo, um maior interesse por parte dos professores e alunos em manter os espaços comuns da escola mais limpos e agradáveis a todos. Podemos perceber, também, o quão importante é para os alunos um momento de socialização durante as atividades realizadas, que oportuniza a integração de diversos saberes, onde o conhecimento pode ser de fato concretizado, uma vez que não há uma fragmentação do conteúdo por se tratar de um projeto interdisciplinar. Houve também o despertar para uma conscientização ambiental que antes passava despercebido. Tanto alunos como professores e comunidade escolar 
puderam compreender que a partir de pequenas atitudes contribui-se para fazer do mundo um lugar melhor e mais sustentável começando pelo local até atingir o global. Almejamos com o projeto que os alunos possam ser multiplicadores dessa ideia e reproduzam em seus ambientes de vivência pessoal - sua casa, sua rua, sua comunidade etc - todo o aprendizado alcançado com as discussões.

\section{Referências}

As Transformações no Mundo da Educação. Terra Livre, Publicação semestral da Associação dos Geógrafos Brasileiros, NÚMERO 14. São Paulo: AGB, Jan-Jul/1999. Disponivel em <http://www.agb.org.br/files/TL_N14.pdf\#page=125>. Acesso em 05. Out. 2015.

BORTOLOZZI, Arlêude; Filho, Archimedes Perez . Diagnóstico da Educação Ambiental no Ensino de Geografia. In: Cadernos de Pesquisa, no 109, p. 145-171, março/2000. Disponivel em: <http://www.scielo.br/pdf/cp/n109/n109a07.pdf>. Acesso em 07. Out. 2015.

BRASIL. Parâmetros Curriculares Nacionais da Educação. Meio Ambiente. Brasília: Sem data. MEC. Disponível em: <http://portal.mec.gov.br/seb/arquivos/pdf/meioambiente.pdf>. Acesso em 07. Out. 2015.

NARCIZO, Kaliane Roberta dos Santos. UMA ANÁLISE SOBRE A IMPORTÂNCIA DE TRABALHAR EDUCAÇÃO AMBIENTAL NAS ESCOLAS. Revista Eletrônica do Mestrado em Educação Ambiental, Rio Grande, v. 22, p.86-94, jun. 2009. Disponível em: <http://www.seer.furg.br/remea/article/view/2807/1583>. Acesso em: 06 nov. 2015.

Panorama da educação ambiental no ensino fundamental. Secretaria de Educação Fundamental. Brasília: MEC, $\quad$ SEF, 2001. 149 p. Disponível em <http://portal.mec.gov.br/secad/arquivos/pdf/coea/panorama.pdf\#page=17>. Acesso em 07. Out. 2015.

RAMOS, Margarete da Silva; RAMOS, Ronaldo da Silva. EDUCAÇÃO AMBIENTAL E A CONSTRUÇÃO DA SUSTENTABILIDADE. Visões, Macaé, v. 1, n. 4, p.1-13, jun. 2008. Disponível em: <http://www.fsma.edu.br/visoes/ed04/4ed_Educacao_Margarete_Ronaldo.pdf>. Acesso em: 06 nov. 2015.

SATO, M. Educação Ambiental. São Carlos: Rima, 2002. 